\title{
Colchicine-induced mutation for new line development of tropical maize (Zea mays L.)
}

\author{
${ }^{1}$ Rahajeng, S.M., ${ }^{2, *}$ Sugiharto, A.N. and ${ }^{2}$ Wardyati, T. \\ ${ }^{1}$ Indonesian Center for Agricultural Training Ketindan, Lawang, Malang \\ ${ }^{2}$ Plant Breeding and Biotechnology, Faculty of Agriculture, Brawijaya University, Malang
}

\begin{abstract}
Article history:
Received: 20 October 2020

Received in revised form: 9

November 2020

Accepted: 21 November 2020

Available Online: 11 April

2021
\end{abstract}

Keywords:

Colchicine induction,

Tropical corn-mutant lines, Heterosis

DOI:

https://doi.org/10.26656/fr.2017.5(2).594

\begin{abstract}
This research aimed to identify colchicine-induced tropical Yellow Corn characters and their potential in superior traits development. Single cross was applied to colchicine mutant line with tester line, INOAXM2 yellow and white seeds, to observe and test the characters enrichment of colchicine mutant, while pure line tester of sweet corn (OP-SBX) was used to observe the enhancement of germination and growth rate. Analysis of various quantitative data was determined using $\mathrm{F}$ test at the level of 5\%, continued with Least Significant Difference Test (LSD) at the level of 5\%. Potential characters and its inheritance pattern were determined by a descriptive statistical approach. Overall, germination and growth test of mutant show significant improvement when mutant crossed with tester lines. According to qualitative characters analysis of mutant line and its single way, it is found that glum colour is influenced by the male parent (Paternal Effect), while seed colour is determined by the female (Maternal Effect). From mutant M1 to M4, quantitative mutant (INFM) characters showed significant differences between lines within one generation and revealed improvements in single cross progeny. Single cross between colchicine line and tester mutant (IONAXM2) presents significant differences in all cobs characters (cob length, number of seeds in a row, number of rows, cob dry weight, and weight of 100 seeds (g) and reveals higher value compared to other lines. Mid-parent heterosis of single cross progeny of mutants was high for cob dry weight, those were $202.38 \%$ and $166.67 \%$. The chromosomes observation of pink and yellow seeds of colchicine mutants revealed the presence of diploid, triploid, and euploid chromosomes, which verify chromosomal changes inside colchicine mutant lines.
\end{abstract}

\section{Introduction}

Indonesian high demands of Zea mays L. is implied in maize intensification program, altogether with rice and soybean. High productivity becomes the primary breeding target, as well as biotic and abiotic stresses resistance, and nutritional properties improvement. On the other hand, conventional plant breeding with self and cross-pollination is well known to be time-consuming and generates less variety. Therefore, alternative approaches to obtain efficient maize lines are continuing to be developed progressively. A research conducted in 1985; successfully streamlines the time needed in maize breeding by using doubled-haploid resulted from androgenesis (Dieu and Beckert, 1986). In cereal anther culture, one critical step to produce the doubled-haploid plant is chromosomes doubling on haploid cell or tissue at a certain stage (Obert and Barnabás, 2004). Several studies have been conducted to investigate whether colchicine treatment gives an impact on the anther culture of several kinds of cereal, such as wheat, maize, rice and triticale. Those chromosomal doubling presenting better phenotypic characters of mutant.

Colchicine is widely used as a mutagen in chromosome multiplication, both in-situ and in-vitro, as colchicine is reported to be able to disrupt mitotic phase of cell division by inhibiting spindle fibres formation and polar migration in chromosomes. Colchicine treatment in maize seeds or plantlets can double chromosomes number in tassel or maize cobs, but sometimes both are not successful and caused failed self-pollination (Wan et al., 1989; Barnabas et al., 1999). High mortality and abnormal plant development are also found in plant populations treated with colchicine. However, Wan et al. (1989) and Wan and Widholm (1995) in Barnabas et al. (1999) reported restoration of genetic stability of doubled-haploid maize plants that have high-frequency 
inheritance, through embryogenic colchicine treatment on haploid microspores callus. Optimal embryo induction can be obtained through a combination of four factors, including genotype, colchicine concentration in the pre-treatment medium, colchicine treatment duration, and embryo induction media. Colchicine pre-treatment on maize anthers can be used to induce in-vitro chromosome multiplication (Mohammadi et al., 2007).

The effectiveness of colchicine in increasing genetic diversity of many strategic commodities, in term of lines development with high productivity by increasing the number of chromosomes, is the basis of colchicine usage as mutagen for new tropical Yellow Corn line development, to obtain hybrid characters. The application of colchicine for maize line development is expected to shorten the breeding time. Some patterns of inheritance, such as additive, dominant, and epistatic, need to be carefully identified to assist selection of breeding methods that will be used. This research aimed to identify colchicine-induced tropical Yellow Corn characters and their potential in superior traits development. Qualitative traits were analysed by using a descriptive statistical approach, which presented in a frequency distribution diagram. Analysis of various quantitative data was determined using F-test at the level of $5 \%$, continued with Least Significant Difference Test (LSD) at the level of 5\%. Heterotic analysis was performed by Mid parent heterosis.

\section{Materials and methods}

The origin line used in this study was Yellow Corn (INF), which is the seventh generation (M7) of Brawijaya University Maize Research Center (BUMRC) inbreed line with its capability to become a potential hybrid parent. The INF was treated with colchicine at $600 \mathrm{ppm}$ and then labelled as the first colchicine mutant generation (M1). The second generation of naturally mutated lines, namely IONAXM2 yellow and white seeds, was used as a tester to observe and test the characters enrichment of colchicine mutant. While pure line tester of sweet corn (OP-SBX) was used to observe the enhancement of germination and growth rate of pink seed colchicine mutant. Integrated Crop Management was applied during maize lines cultivation, which was done by applying cow manure, NPK fertilizer (15-15-15), ZA, SP36, KCl, fungicides, and insecticides. The seeds were grown in 75 $\mathrm{cm}$ inter-row spacing and $15 \mathrm{~cm}$ inter-plant spacing, with each type, consists of 90 plants. The observations were done by single plant method and each plant in the experimental plot was observed. In this study, single cross method was applied to the accession and stopped when the silk and tassel entered its receptive and anthesis period. The tassels were covered using paper to collect pollen, while the silks were covered using transparent plastic to prevent the pistils from being pollinated by other plants. Pollination must be done quick and carefully to achieve high yield. Quantitative and qualitative characters were observed in plants and cobs of the offspring, from M1 to M4. Chromosomal alteration was observed in mutant sprouts roots by squash method. The roots of the sprouts were cut \pm 2 $\mathrm{mm}$, then fixed with Carnoy fixative (6 ethanol:3 chlorophome: 1 Glacial Acetic Acid) for 12 hours. After fixation, the root tip was softened with $2 \mathrm{~N} \mathrm{HCl}$ for $1-3$ minutes then placed on a glass slide and sprinkled with $2 \%$ aceto orcein.

\section{Results and discussion}

\subsection{Germination and seed viability}

Observation on first mutant generation (M1) performance reveals alteration in characters, and it was inherited continuously to M3, including pink seed colour emerged from M2. These phenotypic changes in M1 became pre-assumption of mutation caused by colchicine induction. Genetic diversity improvement due to mutation can be utilized for maize line development with superior traits. Germination and viability test are included in a series of tests to obtain lines with superior traits. According to Eltayeb (2018), Saenong (2018) and Hameed et al. (2008), seed quality is determined by genetic, physical, and physiological qualities. Furthermore, physiological quality is specified by the level of viability, including germination and seed vigor. The growth and development of plants during germination phase greatly affect the plant survival success (Koes and Komalasari, 2015). Germination and viability of M4 colchicine mutant lines were identified and compared to mutants' expression of from previous generations. In the M4, single cross was applied using other mutant lines, to identify whether characters were enriched and improved when it is crossed to another line. The M4 and M5 mutant generations can be used as a source for superior traits assembly because this generation has experienced genetic stability, and being used as parent line in plant breeding (Lestari, 2016). The maize lines used in M4 crossing were yellow seeds of (1) M3 colchicine mutant line (INFM3YP), M3 colchicine mutant crossed with mutant line tester (IONAXM2): (2) yellow seeds (IonAxM2yellow X INFM3Pink) and (3) white seeds (IonAXM2White X INFM3YP). Except for the mutant seeds, non-mutant seeds (INF) were used as a control, and another tester line used was the pure line of sweet corn (OP-SBX), to identify the effect of another line to the improvement of germination and growth rate 
in pink seeds.

The germination and viability test as seen in plants growth indicates that the rate of both characters increased in colchicine mutant lines from generation to generations of those experienced crossing or recombination with another line (Table 1). The number of growing plants of M1 generation has decreased by $72.36 \%$, which was assumed as the plants' response in vigor to colchicine treatment. The higher the colchicine concentration applied, the lower rate of the plant's growth. The pink coloured seeds emerged in M2 generation, notably had a combination of yellow and pink seeds (YP) in one cob. Natural mutant, the (IOANXM2) yellow and white seeds, had a high germination rate for $92 \%$ and $95 \%$, respectively. On the other hand, IOANXM2 white seeds mutant had exceptionally low growth rate, at the number of $9.86 \%$, which was caused by albino expression properties (Figure 1), and generates plant death at the age of 15 DAS.

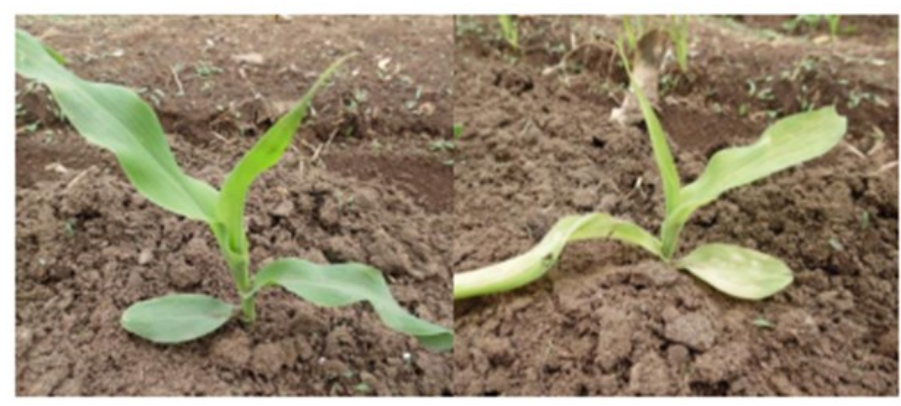

Figure 1. Normal and albino performances of IONAX lines

Pink-coloured seeds of Mutant M3 (INFM3) had the lowest germination and growth rate, $0.87 \%$ and $58.6 \%$, respectively, compared to the yellow seeds. Colchicine induced mutation is known in doubling the number of chromosomes (polyploidy), which resulted in larger plant size, higher vitamin concentration, but generally also reduces fertility (Lestari, 2016). The germination and growth rate of the offspring of (INFM3) pink seeds with mutant (IONAXM2) yellow seeds, which was

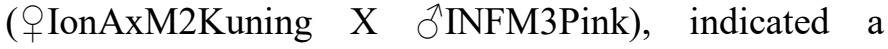
significant increase in germination and viability up to $100 \%$, as well as the offspring of (INFM3YP), crossed with mutant (IONAXM2) white seeds, (PIonAXM2White X ठINFM3YP). Likewise, the germination capacity and growth performance of the M4 colchicine mutant (Sib INFM3YP) yellow seed, shows an increase up to $91.33 \%$ and $90 \%$, respectively, from the previous values of $52.43 \%$ and $64.03 \%$.

To strengthen pre-assumption about the effect of another line in germination and growth rate improvement of colchicine induced mutant, the test was also performed to pink seed by applying single cross with sweet corn pure line (OP-SBX). As the Dent Corn and Sweet Corn type of seeds expressed by the offspring (M5), the test was then performed to pink coloured seeds of both types. The result revealed that both pink seed types enhanced their germination and growth rate, up to $18 \%$ and $100 \%$, respectively. The interesting fact about the colchicine mutant seeds, according to the chromosome observation of yellow and pink mutant seeds; it was known that both seed colours had triploid, mixoploid (diploid and triploid), and euploid

Table 1. Germination and growth rate of non-mutant (INF), M3 and M4 generations

\begin{tabular}{|c|c|c|}
\hline Maize Lines & Germination rate $(\%)$ & Viability $(\%)$ \\
\hline Non-Mutant (INF) & 100 & 100 \\
\hline \multicolumn{3}{|l|}{ Mutant M5 generation: } \\
\hline$(($ P Sib INFM3) X (OP-SBX)) Dent Corn & 14 & 14 \\
\hline$(($ Q Sib INFM3) X (OP-SBX)) Sweet Corn & 18 & 18 \\
\hline$((q \mathrm{OP}-\mathrm{SBX}) \mathrm{X}$ Sib INFM3)) Dent Corn & 10 & 10 \\
\hline$((+\mathrm{OP}-\mathrm{SBX})$ X Sib INFM3 $))$ Sweet Corn & 10 & 10 \\
\hline \multicolumn{3}{|l|}{ Mutants M4 generation: } \\
\hline (Sib INFM3 YP) yellow seed & 91.33 & 90 \\
\hline (qIonAxM2 Kuning X $\overbrace{}^{\lambda}$ INFM3Pink) yellow seed & 100 & 100 \\
\hline (†IonAXM2 Putih X $\overbrace{}^{\Uparrow}$ INFM3YP) yellow seed & 100 & 100 \\
\hline \multicolumn{3}{|l|}{ Mutants M3 generation: } \\
\hline INFM3 pink seed & 0.87 & 58.06 \\
\hline INFM3 yellow seed YP cob (INFM3YP) & 52.43 & 64.03 \\
\hline INFM3 yellow seed full yellow cob & 77.08 & 59.46 \\
\hline INF non-mutant & $93 \%$ & 92.31 \\
\hline IONAXM2 yellow seed & 92 & 92.31 \\
\hline IONAXM2 white seed & 95 & 9.86 \\
\hline \multicolumn{3}{|l|}{ Mutants M1 Generation: } \\
\hline INFM1 & - & $72.63 \%$ \\
\hline
\end{tabular}


chromosomes. Thus, it is confirmed that colchicine mutant encounter chromosomal alterations. It is known that plant ploidy is a result of increased gene dosage; a research result by Guo et al. (1996) confirms that the increase of genes dosage through a series of ploidy can increase gene expression proportionally. Polyploidy performs a higher level of enzyme activity compared to its diploid, which affects gene expression improvement in each cell and is proportional to the gene dosage given at the ploidy level. It is shown in most genes in aneuploid (monoploid, diploid, triploid, and tetraploid) of maize.

Germination and growth rate of colchicine mutant lines in this study indicates that the reduction of germination and growth rates due to colchicine induction could be increased by crossing mutants with other lines. Likewise, there is an indication of the domination of female parents (Maternal Effect) in increasing germination and growth rate of colchicine mutant. This result corresponds to other findings from Chettoor et al. (2016) and Eagles and Hardacre (1978), which state that the domination of female parents is substantial in seed (kernel) development, especially in the percentage of germination.

\subsection{Qualitative traits of mutants}

The observation of glum colour in tested lines reveals that most of the lines used in this study had reddish-green glum, except the glum colour of the natural mutant line (IONAXM2), which was yellowgreen seeds. Glum discoloration occurred in mutants ( IONAXM2yellow X §INFM3 Pink), which had a reddish-green glum colour as their male parent (INFM3pink) (Table 2). Based on these results, it is assumed that the qualitative nature of glum colour is influenced by the genetics of male parents (Paternal Effect), as the M1 glum colour (IONAX) turned reddishgreen to green in the M2, and changes back to reddishgreen as the M1 and its male parent.

According to Mustofa et al. (2013) and Nugroho et al. (2013), the difference in the appearance of qualitative characters is determined by the role of genes in each maize genotype, both monogenic and oligogenic, which means that it is not affected by environmental factors. The colour variation of glum and anther, from light green to purple, is an important factor in determining genetic diversity of phytochemical traits. Plant tissue colour, especially flower colour, is a source of many phytochemicals, such as chlorophyll, carotenoids, flavonoids, and anthocyanins (Tanaka et al., 2008; Duangpapeng et al., 2018). Maize contains anthocyanins, and anthocyanin synthesis requires the presence of $\mathrm{Pl}$ allele and members of the $\mathrm{R} / \mathrm{B}$ regulatory gene group. Plants that carry dominant $\mathrm{B}$ allele and non-mutant (wild type) $\mathrm{Pl}$ allele, show dark purple colour on all vegetative parts of the plant, including leaves, stems, bark/husk, and glum tassel (Cocciolone et al., 1993). Besides the presence of glum colour, observation on seed colour was done to identify qualitative characters and patterns of inheritance in the next generation of colchicine mutant. Comparison between seed colour performance on the cobs of each line and RHS colour chart shows that nonmutant (INF) line has a yellow-orange (Strong Orange/ SO 25B) and orange (Stronge Orange/SO 25A) seed colour, while the mutant line (Sib INFM3YP) was identified contains a pink colour on the cob with varying amounts per-ear inherited from generation to generation as a result of colchicine induction treatment. Observations were applied on the cob population produced from each cross between cobs and between lines, 20-50 cobs each from the M4 generation.

The values presented in Table 3 are the percentage of the number of colours appeared on the cob produced in each line in the M4 generation and describes the number of seeds on each ear for M3 generation. Seed colour identification indicated that non-mutant (INF) had a cob population of $100 \%$ containing orange seeds (SO 25A) and $93 \%$ containing orange seeds (SO 25B), which means that there are $7 \%$ cobs of non-mutant lines contained only orange seeds in one cob. Mutant M2 consisted of a cob population that each had 100\% yellow -orange and bright orange seed colours, while $1 \%$ of the population or one cob of all cobs produced contained yellow and pink seed colours (Figure 2). The expressed pink colour is thought to be one of colchicine treatment effects at the P1 locus, which contains responsible genes for flower and seed colour regulation.

Mutant M5 generation, which resulted from selfing and sib mating between ( IONAXM2yellow X ऽINFM3 Pink) and (PIONAXM2White X ÎINFM3

Table 2. Glum colour of non-mutant, mutant and tester lines used in the study

\begin{tabular}{|c|c|c|c|c|c|}
\hline Maize lines & Glum colour & Maize lines & Glum colour & Maize lines & Glum colour \\
\hline INF Non-mutant & reddish-green & IONAX non-mutant & reddish-green & Sib INFM3YP & Reddish-green \\
\hline INFM3 pink seed & reddish-green & IONAXM1 yellow seed & reddish-green & $\begin{array}{l}\text { (IONAXM2 yellow X } \\
\text { ठINFM3 Pink) }\end{array}$ & reddish-green \\
\hline $\begin{array}{l}\text { INFM3YP yellow } \\
\text { seed }\end{array}$ & reddish-green & IONAXM2 yellow seed & green & $\begin{array}{l}\text { (IONAXM2 white X } \\
\text { İINFM3 YP) }\end{array}$ & reddish-green \\
\hline $\begin{array}{l}\text { INFM3 yellow seed } \\
\text { Full yellow cob }\end{array}$ & reddish-green & IONAXM2 white seed & reddish-green & & \\
\hline
\end{tabular}


Table 3. Seed colour variation from cob' population yielded and average number of seeds per colour category for non-mutant (INF) and colchicine mutants M2, M3, M4, based on RHS Colour Chart

\begin{tabular}{|c|c|c|c|c|c|c|}
\hline \multirow[b]{2}{*}{ Maize lines } & \multicolumn{6}{|c|}{$\%$ Seed Colour on Cob (in Cobs population) } \\
\hline & $\begin{array}{r}\text { PGY } \\
10 \mathrm{D} \\
\end{array}$ & $\begin{array}{c}\text { BY } \\
12 \mathrm{~B} \\
\end{array}$ & $\begin{array}{c}\mathrm{SO} \\
12 \mathrm{~B} \\
\end{array}$ & $\begin{array}{c}\mathrm{SO} \\
25 \mathrm{~A} \\
\end{array}$ & white & $\begin{array}{r}\text { SP } \\
49 \mathrm{~A} \\
\end{array}$ \\
\hline Non-mutant (INF) & & & 93.33 & 100 & & \\
\hline \multicolumn{7}{|l|}{ M4 Generation } \\
\hline Mutant Sib INFM3YP & & & 64.44 & 87.50 & & 46.58 \\
\hline Mutant ( IONAXM2 yellow X $\overbrace{}^{\lambda}$ INFM3 Pink) & 47.15 & 45.08 & 95.12 & 73.27 & 45.23 & 5.85 \\
\hline Mutant ( IONAXM2 white X ${ }^{1}$ INFM3 YP) & 46.02 & 54.67 & 100 & 81.18 & 43.27 & 15.25 \\
\hline \multirow[b]{2}{*}{ M3 Generation } & \multicolumn{6}{|c|}{ The average number of seed in each colour category } \\
\hline & $\begin{array}{c}\text { Yellow Seed } \\
\text { Purple-Embryo }\end{array}$ & $\begin{array}{c}\text { BY } \\
12 \mathrm{~B} \\
\end{array}$ & $\begin{array}{c}\mathrm{SO} \\
25 \mathrm{~B} \\
\end{array}$ & $\begin{array}{r}\mathrm{SO} \\
25 \mathrm{~A} \\
\end{array}$ & white & $\begin{array}{c}\text { SP } \\
49 \mathrm{~A} \\
\end{array}$ \\
\hline INFM3 pink seed & 1.15 & & 216.30 & & & 48.95 \\
\hline INFM3YP yellow seed & 0.60 & & 188.52 & & 44 & 59.79 \\
\hline IONAX M2 yellow seed & & & 196.71 & & 69 & \\
\hline IONAX M2 white seed & & & 111 & & 80 & \\
\hline \multirow[b]{2}{*}{ M2 Generation } & \multicolumn{6}{|c|}{ \% Seed Colour on Cob (in Cobs population) } \\
\hline & & & $\begin{array}{l}\text { LOY } \\
25 \mathrm{D}\end{array}$ & $\begin{array}{l}\mathrm{BO} \\
25 \mathrm{C} \\
\end{array}$ & & YP \\
\hline INFM2 & & & 100 & 100 & & $1 \%$ \\
\hline
\end{tabular}

PGY $=$ Pale Greenish Yellow, BY = Brilliant Yellow, LOY $=$ Light Orangish Yellow, BO = Brilliant Orange, SO = Strong Orange, $\mathrm{SP}=$ Strong Pink

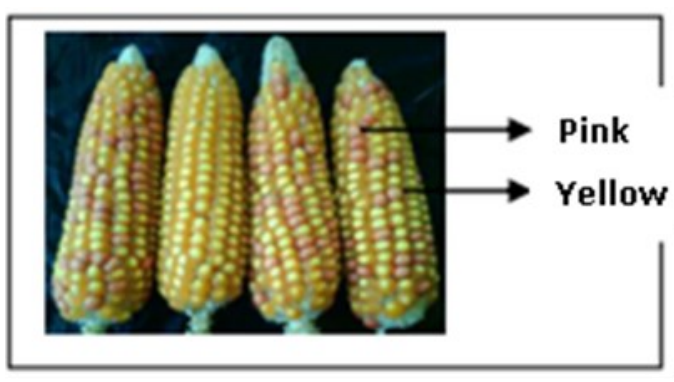

Figure 2. Colchicine M2 with Yellow Pink (YP) seed colour

YP), has a number of cobs with the same colour combination, those were orange (SO 25A), yelloworange (SO 25B), light yellow (BY 12B), beige (PGY 10D), white and pink (SP 49A), with a higher percentage of pink coloured seeds in maize ( 9 IONAXM2 White $\mathrm{X}$ JINFM3 YP), which was by $15.25 \%$. This value indicates that the pink coloured seed present in $15.25 \%$ out of total $100 \%$ cobs' population yield. The pink colour identified in M2 colchicine mutant (INFM2), inherited to the M3 generation (INFM3) and subsequently found in M4, indicates that red colour expression occurred due to colchicine-induced mutation (Figure 3). In the population of (IONAXM2 yellow X INFM3pink) and (IONAXM2white X INFM3YP) cobs, we found cobs with some seed colour combinations, which are: (1) orange, (2) yellow-orange, (3) orangeyellow, (4) orange-yellow-orange-pink, (5) yellow orange-yellow-white, (6) yellow-yellow-beige-white, (7) orange-yellow-orange-beige-white, (8) orange-yellowyellow-beige, (9) orange-yellow orange-yellow-beigewhite, orange-yellow orange-yellow-beige-white-pink with the percentage and pattern of seed colour in the cob population as described in Table 3 . The most dominant colour and frequently appeared in cob population resulted from crossed-cob are orange-yellow, while the least is pink, in the cob population (IONAXM2 yellow X INFM3 pink). In addition to inherited colours from male and female parents, there are new colours emerged, which are orange, yellow and beige.

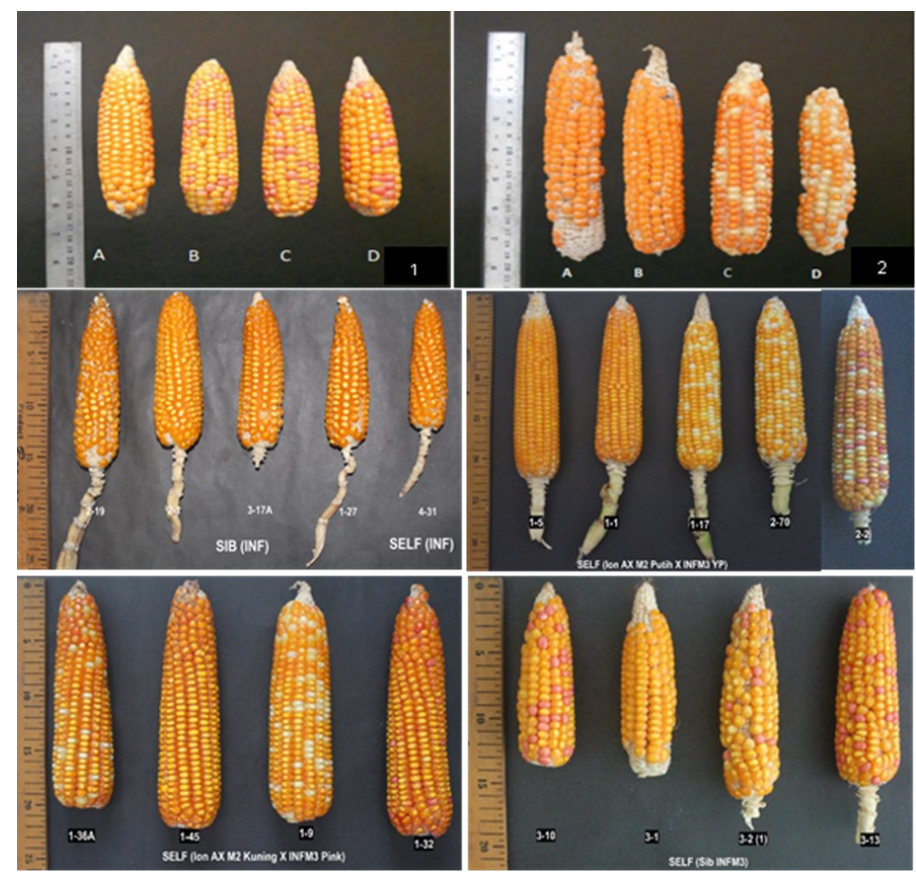

Figure 3. Variation of seeds colour and types of seeds of M3, M4, and M5 generations and non-INF maize lines

The pink colour indicates that mutation affects the expression of seed colour genes. Colour combination produced by crossing between colchicine and natural mutants reveals colour recombination. Seed colour 
variety in each cob shows that each seed of the cob is ruled by different seed colour gene, however, it is still dominated by carotenoid phytochemical genes that express a yellow to orange spectrum. In 2000, a scientific paper written by Ford explains that either carotenoid (yellow pigment) or anthocyanin (red and purple pigments) is responsible to activate metabolic pathways to synthesize yellow, red and purple pigments. On the other hand, while both pathways produce insufficient pigment, white colour will be seen on the seed. Several genes are involved during pigment synthesis; it covers both structural (coding for enzymes) and regulators (also called transcription activators and protein encoders that control the transcription of structural genes). Those four genes in charge namely Pr1, C1, R1 and Y1.

Based on colour combinations seen on two mutant lines, it is concluded that the natural mutants (as female parents) affect significantly compared to colchicine mutants (as male parents), which can be identified from less number of pink seeds expressed in each cob population of the offspring. Qualitative character analysis of single-way mutant crossbreed with other mutant lines indicates that glum character is influenced by the male parent (Paternal Effect), while seed colour is dominated by the female (Maternal Effect). The pink colour character of colchicine mutants is recessive compared to other line suggested that other colchicine mutant characters are also recessive. Colchicine induction is assumed to cause activation of structural genes or transcription factors in the anthocyanin pathway which produces pink colour.

\subsection{Quantitative traits of mutants}

\subsubsection{Plants quantitative traits}

Quantitative traits analysis was done by observing lines' characters performance of the plant and cob. Tested quantitative traits include plant height $(\mathrm{cm})$, number of leaves, leaf length $(\mathrm{cm})$, leaf width $(\mathrm{cm})$, tassel age (DAS), silk age (DAS), and harvest age
(DAS). Result analysis of significant differences of quantitative plant characters of M4 generation shows that between non-mutant and mutant plants have significant differences in characters of plant height, number of leaves, leaf length, leaf width and harvest age (Table 4). The colchicine mutant (Sib INFM3YP) performed the smallest plant height, leaf number, and longest harvesting age, compared to non-mutant lines and combination mutants. Thus, indicates that colchicine contributes significant impact on non-mutant characters. Decreasing colchicine mutant characters had increased when it was crossed with other lines, including in pink seed test from the offspring of colchicine crossed with sweet corn (OP-SBX) line. Analysis from generation to generation shows that colchicine mutant lines experienced variations in plant quantitative characters as shown in Table 5. The M1 generation shows that 600 ppm of colchicine treatment reduce the growth ability, plant height, leaf number, leaf length, leaf width, and tasseling age and silking age, which was then predicted to be caused by mutations or ploidy changes. The M2 mutant had shown an increase in leaf number, leaf width, tasseling age, silking age, and harvest age as the nonmutant line, along with the appearance of pink colour seed on the cob. Sib mating of M3 of INFM3YP ( $\mathrm{Sib}$ INFM3YP), like M4, performed an increase on plants quantitative quality compared to M2 generation, with better values presented in M3 and M4, except the harvest age, which indicated earlier in the M4. The performance of colchicine mutant start showing traits stability, as the M4 or M5 could be used as parent line in new line development (Lestari, 2016).

Characters improvement occurred suggest the existence of heterosis, which is performed from recombination between two crossed lines. Heterosis is the alteration in characters inherited to the next generation, which differ from its parents. Generally, heterosis is a super or hybrid character that performed by the offspring (F1) in terms of production, disease resistance, drought tolerance, harvesting age, and others,

Table 4. Quantitative traits performance of non-mutant and mutant maize lines M4

\begin{tabular}{|c|c|c|c|c|c|}
\hline \multirow[b]{2}{*}{ Parameter } & Non-Mutant & \multicolumn{3}{|c|}{ Mutant } & \multirow{2}{*}{$\begin{array}{c}\mathrm{F} \text { Test } \\
\text { non-mutant } \mathrm{x} \\
\text { mutant }\end{array}$} \\
\hline & (INF) & (SIB INFM3Y) & $\begin{array}{l}\text { (IONAX yellow X } \\
\text { INFM3 Pink) }\end{array}$ & $\begin{array}{c}\text { (IONAX white X } \\
\text { INFM3YP) }\end{array}$ & \\
\hline Plant height $(\mathrm{cm})$ & $128.76^{\mathrm{ab}}$ & $120.47 a$ & $175.72^{\mathrm{c}}$ & $173.19^{\mathrm{c}}$ & $50.22^{\mathrm{n}}$ \\
\hline Leaf number & $11^{\mathrm{b}}$ & $7^{\mathrm{a}}$ & $12^{\mathrm{c}}$ & $12^{\mathrm{c}}$ & $157.68^{n}$ \\
\hline Leaf height $(\mathrm{cm})$ & $65.34^{\mathrm{a}}$ & $83.81^{b}$ & $95.32^{\mathrm{c}}$ & $94.46^{\mathrm{c}}$ & $53.37^{\mathrm{n}}$ \\
\hline Leaf width $(\mathrm{cm})$ & $6.53^{\mathrm{a}}$ & $8.23^{\mathrm{b}}$ & $9.18^{\mathrm{c}}$ & $8.6^{\mathrm{bc}}$ & $23.4^{\mathrm{n}}$ \\
\hline Tasseling age (DAS) & 61 & 62 & 60 & 59 & $0.49^{\text {tn }}$ \\
\hline Silking age (DAS) & 64 & 63 & 62 & 65 & $0.67^{\text {tn }}$ \\
\hline Harvest age (DAS) & $107^{\mathrm{a}}$ & $116^{\mathrm{b}}$ & $101^{\mathrm{a}}$ & $102^{\mathrm{a}}$ & $12.52^{\mathrm{n}}$ \\
\hline
\end{tabular}

The lowercase notation beside the number shows a significant difference in plant characters between non-mutants and mutants. $\mathrm{n}$ $=$ significantly different, $\mathrm{tn}=$ not significantly different 
Table 5. Quantitative traits of mutant plants across generations (M1 to M4)

\begin{tabular}{lccccc}
\hline \multicolumn{1}{c}{ Parameter } & INF non-mutant & INFM1 & INFM2YP & INFM3YP & SIB INFM3YP \\
\hline Plant Height (cm) & 149.52 & 128.8 & 108.18 & 115.4 & 120.47 \\
Leaf number & 12.73 & 10.78 & 12.64 & - & 7 \\
Leaf height (cm) & 81.52 & 76.39 & 72.76 & - & 83.81 \\
Leaf width (cm) & 6.6 & 6.11 & 7.05 & - & 8.23 \\
Tasseling Age (DAS) & 64.91 & $4-8$ days longer & 63.39 & 62.6 & 62 \\
Silking Age (DAS) & 65.95 & $4-8$ days longer & 63.75 & 64.2 & 63 \\
Harvest Age (DAS) & 112.59 & - & 112.08 & 108.87 & 116 \\
\hline
\end{tabular}

due to gene recombination of two different parents (Pradipta, 2007; Makkulawu, 2009; Sutoro and Zuraida, 2013; Siswati et al., 2015; Lestari, 2016; Trihatmojo et al., 2017). Fuzzato et al. (2002) in Makkulawu (2009), states that heterosis and special recombination ability of two crossbred populations depend on the presence of dominant genes in control characters, and diversity among populations. According to these data, it is assumed that quantitative characters of colchicine mutant plants are recessive to the female parent of the natural mutant line, in other words, the genotype of other female parents dominates colchicine mutant lines in terms of plant phenotypes.

\subsubsection{Cobs quantitative traits}

Qualitative and quantitative traits are phenotypic categories of plants controlled by one or certain genes. The patterns of inheritance identification usually completed by observation on plant characters, where quantitative related to morphology are the easiest to observe. Corncobs characters are one point, which is not easily influenced by the environment (conserved), thus it can be used to measure phenotypic characters in maize (Mustofa et al., 2013). A research done by Fatimah et al. (2014), explains about the contribution of xenia (the male parent's influence) that is appeared in the offspring of several combinations of crossings of seed and cob characters, both quantitative (cob weight, and number of seeds per-cob) and qualitative (colour and type of seeds).

In this study, quantitative characters of cob were observed in M3 and M5 generations. Quantitative character analysis of cobs shows that selfing and sib mating between non-mutant and mutant lines showed significant differences on cob length $(\mathrm{cm})$, cob length (seeds), and weight of 100 seeds (g) between types of crosses, while the number of rows (seeds) and dry weight cob $(\mathrm{g})$ presents no significant difference between types of crosses (Table 6). The significant differences in the number of seeds in a row between types of crosses were identified only in non-mutant and mutant lines (SibINFM3YP). Based on the results of the significant difference test, high values were obtained in selfing offspring with significance values of 8.23 and 9.48 for cob length $(\mathrm{cm})$ and the number of seeds in a row (seeds), respectively. Different results of the significant difference test were shown on weight character of 100 seeds, where the real differences were shown on all lines, the higher values were obtained from the selfing results between non-mutant lines and (IONAXM2 White $\mathrm{x}$ INFM3YP), while the values were higher than the results of sib mating obtained in SibINFM3YP and (IONAXM2yellow X INFM3Pink) lines, with a significance value of 114.99

Table 6. Quantitative traits and F-Test of non-mutant and mutant M5

\begin{tabular}{|c|c|c|c|c|c|c|c|c|}
\hline \multirow[b]{2}{*}{ Parameter } & \multirow{2}{*}{$\begin{array}{l}\text { Type of } \\
\text { Cross }\end{array}$} & \multirow{2}{*}{$\begin{array}{l}\text { Non-mutant } \\
\text { INF }\end{array}$} & \multicolumn{3}{|c|}{ Mutant Lines } & \multicolumn{3}{|c|}{ F Test } \\
\hline & & & Sib INFM3 & $\begin{array}{l}\text { (IONAXM2yellow } \\
\text { X INFM3Pink) }\end{array}$ & $\begin{array}{c}\text { (IONAXM2white } \\
\text { X INFM3YP) }\end{array}$ & $\begin{array}{l}\text { Between } \\
\text { cross type }\end{array}$ & $\begin{array}{l}\text { Between } \\
\text { lines }\end{array}$ & Interaction \\
\hline \multirow{2}{*}{$\begin{array}{l}\text { Cob length } \\
(\mathrm{cm})\end{array}$} & Selfing & $12.41^{\mathrm{aA}}$ & $14.59^{\mathrm{cdAB}}$ & $20.7^{\mathrm{fC}}$ & $20.55^{\text {efC }}$ & \multirow{2}{*}{$8.23^{n}$} & \multirow{2}{*}{$109.05^{\mathrm{n}}$} & \multirow{2}{*}{$1.8^{\operatorname{tn}}$} \\
\hline & Sib mating & $12.8^{\mathrm{abA}}$ & $12.96^{\mathrm{abcAB}}$ & $18.91^{\mathrm{eC}}$ & $19.32^{\mathrm{efC}}$ & & & \\
\hline \multirow{2}{*}{$\begin{array}{l}\text { Number of } \\
\text { seeds in row }\end{array}$} & Selfing & $20^{\mathrm{abcA}}$ & $21^{\text {bcdAB }}$ & $29^{\mathrm{eC}}$ & $30^{\mathrm{eC}}$ & \multirow{2}{*}{$9.48^{\mathrm{n}}$} & \multirow{2}{*}{$37.62^{\mathrm{n}}$} & \multirow{2}{*}{$0.7^{\text {tn }}$} \\
\hline & Sib mating & $15^{\mathrm{aA}}$ & $19^{\mathrm{abAB}}$ & $28^{\mathrm{eC}}$ & $27^{\mathrm{eC}}$ & & & \\
\hline \multirow{2}{*}{$\begin{array}{l}\text { Number of } \\
\text { rows }\end{array}$} & Selfing & $10^{\mathrm{A}}$ & $12^{\mathrm{B}}$ & $14^{\mathrm{C}}$ & $13^{\mathrm{BC}}$ & \multirow{2}{*}{$1.58^{\mathrm{tn}}$} & \multirow{2}{*}{$14.133^{\mathrm{n}}$} & \multirow{2}{*}{$2.06^{\mathrm{tn}}$} \\
\hline & Sib mating & $11^{\mathrm{A}}$ & $12^{\mathrm{B}}$ & $13^{\mathrm{C}}$ & $13^{\mathrm{BC}}$ & & & \\
\hline \multirow{2}{*}{ Dry weight (g) } & Selfing & $59.34^{\mathrm{A}}$ & $132.5^{\mathrm{B}}$ & $305.13^{\mathrm{C}}$ & $248.25^{\mathrm{C}}$ & \multirow{2}{*}{$3.04^{\text {tn }}$} & \multirow{2}{*}{$90.07^{\mathrm{n}}$} & \multirow{2}{*}{$3.43^{\text {tn }}$} \\
\hline & Sib mating & $75.38^{\mathrm{A}}$ & $112.19^{\mathrm{B}}$ & $234.3^{\mathrm{C}}$ & $251.24^{\mathrm{C}}$ & & & \\
\hline \multirow{2}{*}{$\begin{array}{l}\text { Dry weight of } \\
100 \text { seeds }(g)\end{array}$} & Selfing & $30.5^{\mathrm{bcdA}}$ & $29.77^{\mathrm{abB}}$ & $30.1^{\mathrm{abcBC}}$ & $37.33^{\mathrm{fD}}$ & \multirow{2}{*}{$114.99^{\mathrm{n}}$} & \multirow{2}{*}{$114.01^{\mathrm{n}}$} & \multirow{2}{*}{$88.3^{\mathrm{n}}$} \\
\hline & Sib mating & $28.98^{\mathrm{aA}}$ & $36.79^{\mathrm{efB}}$ & $37.35^{\mathrm{fBC}}$ & $35.92^{\mathrm{eD}}$ & & & \\
\hline
\end{tabular}

The lowercase notation above the number shows a significant difference in the quantitative character of cobs between types of crosses while the uppercase notation above the number shows a significant difference between the maize lines. $\mathrm{n}=$ significantly different, $\mathrm{tn}=$ not significantly different 
Selfing and sib mating are crossing methods to produce offspring in the same genotype as their parents (Latta and Kermit, 1993; Anggraeni, 2017). Selfing and sib mating is used during breeding to get accession, which characters resemble their parents, including the process of seeds rejuvenation (Sutoro and Zuraida, 2013). The significantly different values of cob' characters show that the single-way cross between colchicine mutants and natural mutants generates improved characters (heterosis), which is heritable to the next generation. Most of the values of the characters are greater in selfing offsprings, which indicates that there is no inbreeding depression in the M4 generation mutants. Inbreeding depression is a condition in which plants experience segregation and reduced vigor, where accessions that are self-pollinated show various deficiencies such as shorter plants, tend to fall, sensitive to diseases, and various other undesirable characters (Poehlman and Suwarno, 2008; Rahmawati et al., 2014). Cob length $(\mathrm{cm})$, number of seeds in rows (seeds), and weight of 100 seeds $(\mathrm{g})$ determine significant differences between types of crosses and lines, indicate that type of cross (selfing or sib mating) and the maize lines affect the number of rows. Essentially, almost all reported data in all parameters and lines, confirm that selfing resulted in higher value than sib mating. In theory, selfing increases homozygosity at a rate of 0.50 per generation. During selfing, there is a process called "genetic cleaning" mechanism, in which the genome size is significantly reduced, and the main missing component is Transposable Element (TE). Roessler et al. (2019) documented an extraordinary loss of genomic size for maize strains, as much as DNA from the genomes of three Arabidopsis thaliana, averaged over just a few generations of selfing. This underlies the character of the selfing results described above is the basic character possessed by the lines tested in this study.

Compared to its parents, it was found that heterosis character of corn' cobs emerged in colchicine mutant
(INFM3) that was crossed with other mutants, as shown in its plants quantitative characters. In the previous study, other lines used for crossbreeding were natural mutants, as female parents. This research also found that the M4 offspring had a significant increase on cob's quantitative characters, especially in dry weight (Table 7). Mid Parent Heterosis (MPH) were found high in dry weight length and dry weight of 100 seeds, with the highest MPH revealed in dry weight by the cross of (IONAXM2yellow X INFM3Pink), it was 202.38\%. Previous studies state that quantitative traits are influenced by genetics of male parents, however this study indicates that heterosis is inherited from female parents. To strengthen the presumption about contribution of female or male parents on colchicine mutant heterosis inheritance, another research should be done to assure parental influence in heterosis inheritance.

\section{Conclusion}

Colchicine mutant lines show significant differences in characters between tested lines in M4. It was revealed that the characters were altered when it crossed to other lines. Non-mutant INF performed alterations in characters due to mutations, and it was confirmed by the presence of pink seeds in M2 and the decreased of quantitative traits since M1. Chromosomal observations in yellow and pink seeds affirmed the mutation, where triploid and euploid chromosomes were confirmed. Pink seeds, as the newly emerged seed color, performed low germination and growth rate. However, the germination and growth rate of pink seeds shows higher in colchicine mutants (Sib INFM3) crossed with pure lines (OP-SBX).

The significant differences were seen on colchicine mutant plant (INFM3) characters between lines and generations include the characters of plant height, number of leaves, leaf length and leaf width, however, all those characters are notable while it was crossed with other lines. The value of plant characters shows higher,

Table 7. Quantitative traits and Heterosis of cobs performed by single-way mutant cross

\begin{tabular}{|c|c|c|c|c|c|c|}
\hline \multirow[b]{2}{*}{ F1 Hybrids } & \multirow[b]{2}{*}{$\begin{array}{l}\text { Cobs length } \\
\quad(\mathrm{cm})\end{array}$} & \multirow[b]{2}{*}{$\begin{array}{l}\text { Dry weight } \\
\text { (g) }\end{array}$} & \multirow{2}{*}{$\begin{array}{c}\text { Dry weight } \\
\text { of } 100 \text { seeds } \\
(\mathrm{g})\end{array}$} & \multicolumn{3}{|c|}{ Heterosis $(\%)$} \\
\hline & & & & $\begin{array}{l}\text { Cobs length } \\
(\mathrm{cm})\end{array}$ & $\begin{array}{l}\text { Dry weight } \\
(\mathrm{g})\end{array}$ & $\begin{array}{l}\text { Dry weight of } \\
100 \text { seeds }(\mathrm{g})\end{array}$ \\
\hline \multicolumn{7}{|l|}{ Mutant M3 } \\
\hline INFM3YP yellow seed & 15.48 & 96.93 & 30 & & & \\
\hline INFM3 pink seed & 12.71 & 70.47 & 21 & & & \\
\hline IONAXM2 yellow seed & 15.77 & 84.5 & 24 & & & \\
\hline IONAXM2 white seed & 17.4 & 91.5 & 24 & & & \\
\hline \multicolumn{7}{|l|}{ Mutant M5 } \\
\hline Sib (Sib INFM3YP) & 12.96 & 112.19 & 36.79 & -16.28 & 15.74 & 22.63 \\
\hline $\begin{array}{l}\text { Sib ((IONAXM2 yellow X } \\
\text { INFM3 Pink }))\end{array}$ & 18.91 & 234.3 & 37.35 & 32.79 & 202.38 & 66 \\
\hline $\begin{array}{l}\text { Sib ((IONAXM2 white X } \\
\text { INFM3YP)) }\end{array}$ & 19.32 & 251.24 & 35.92 & 17.52 & 166.67 & 33.04 \\
\hline
\end{tabular}


as single cross with other mutant lines as tester applied. Dry weight cobs as a marker of maize productivity demonstrate significant higher value, performed in the offspring of mutant recombination with the natural mutant female (OIONAXM2 yellow X INFM3 pink) and ( IONAXM2 white X INFM3P), and has their Mid Parent Heterosis value of $202,38 \%$ dan $166,67 \%$, respectively. Heterosis traits is performed by the colchicine-induced mutant, which is potential to be used in new lines development to improve lines performance in productivity, pest and disease resistance, and nutritional value, all those characters' upgrade revealed in seed color, as colchicine induction is assumed to cause activation of structural genes or transcription factors in the anthocyanin pathway, which led to express pink colour.

\section{Acknowledgments}

This research was partly funded by PPUPT project (2018-2020). The authors would like to thank Aili, Anggraeni, and Rizqiningtyas, for the previous works in supporting this research.

\section{References}

Barnabás, B. Obert, B. and Kovács, G. (1999). Colchicine, an efficient genome-doubling agent for maize (Zea mays L.) microspores cultured in anthero. Plant Cell Reports, 18, 858-862. https:// doi.org/10.1007/s002990050674

Chettoor, A.M., Phillips, A.R., Coker, C.T., Dilkes, B. and Evans, M.M.S. (2016). Maternal Gametophyte Effects on Seed Development in Maize. Genetics, 204(1), 233-248. https://doi.org/10.1534/ genetics.116.191833

Cocciolone, S.M. and Cone, K.C. (1993). Pl-Bh, an Anthocyanin Regulatory Gene of Maize That Leads to Variegated Pigmentation. Genetics, 135(2), 575588. https://doi.org/10.1093/genetics/135.2.575

Dieu, P. and Beckert, M. (1986). Further Studies of Androgenetic Embryo Production and Plant Regeneration From In Vitro Cultured Anthers in Maize (Zea mays L.). Maydica, 31(3), 245-259.

Duangpapeng, P., Ketthaisong, D., Lomthaisong, K., Lertrat, K., Scott, M.P. and Suriharn, B. (2018). Corn Tassel: A New Source of Phytochemicals and Antioxidant Potential for Value-Added Product Development in the Agro-Industry. Agronomy, 8 (11), 242. https://doi.org/10.3390/agronomy8110242

Eagles, H.A and Hardacre, A.K. (1979). Genetic Variation in Maize (Zea Mays L) for Germination and Emerged at $10^{\circ} \mathrm{C}$. Euphytica, 28, 287-295. https://doi.org/10.1007/BF00056585
Eltayeb, Z. (2018). Germination of Corn (Zea mays L.) Cultivars Seed and Its Relationship to Field Performance under Semi - Arid Conditions. IOSR Journal of Agriculture and Veterinary Science, 11 (6), 32-40.

Fatimah, F., Sugiharto, A.N. and Ainurrasjid. (2014). Xenia Effect in Some Lines of Maize (Zea mays L.) Pollination on Maize Seed and Cob. Crop Agro, 2 (2), 103-110.

Ford, R.H. (2000). Inheritance of Kernel Color in Corn: Explanations and Investigations. The American Biology Teacher, 62(3), 181-188. https:// doi.org/10.2307/4450870

Guo, M., Davis, D. and Birchler, J.A. (1996). Dosage Effects on Gene Expression in a Maize Ploidy Series. Genetics, 142(4), 1349-1355. https:// doi.org/10.1093/genetics/142.4.1349

Hameed, A., Shah, T.M., Atta, B.M., Haq, M.A. and Sayed, H. (2008). Gamma Irradiation Effects on Seed Germination and Growth, Protein Content, Peroxidase and Protease Activity, Lipid Peroxidation in Desi and Kabuli Chickpea. Pakistan Journal of Botany, 40(3), 1033-1041.

Koes, F. and Komalasari, O. (2015). Effect of Seed Storage and Invigoration on Maize Seeds Quality presented at the Seminar on Cerealia. Indonesia.

Lestari, E.G. (2016). Plant Breeding through Induced Mutation and In-Vitro Culture, p. 1 - 58. Indonesia: IAARD press.

Makkulawu, A.T. (2009). Development of Pure Line Selection Method for Drought Tolerant Corn (waxy corn) and opaque-2 (oo) Gene Introgression with SSRs Markers (Simple Sequence Repeats). Indonesia: Bogor Agricultural Institute, Thesis.

Mohammadi, P.P., Moieni, A. and Javaran, M. J. (2007). Colchicine induced embryogenesis and doubled haploid production in maize (Zea mays L.) anther culture. Iranian Journal of Biotechnology, 5(3), 140146.

Mustofa, Z., Budiarsa, I.M. and Samdas, G.B.N. (2013). Genetic Variation of Maize (Zea mays L.) Cultivated in Village of Jono Oge Based on the Cob Phenotypic Characters. E Journal of Biology, 1(1), 33-41.

Nugroho, S., Barmawi, M. and Sa'diyah, N. (2013). Segregation of Soybean (Glycine max L. Merrill) Agricultural Characteristics of F2 of Yellow Bean and Taichung. Indonesia: Faculty of Agriculture, Lampung University, Thesis.

Obert, B. and Barnabás, B. (2004). Colchicine induced embryogenesis in maize. Plant Cell, Tissue and Organ Culture, 77, 283-285. https://doi.org/10.1023/ B:TICU.0000018399.60106.33 
Rahmawati, D., Yudistira, T. and Mukhlis, S. (2014). Inbreeeding Depression of Phenotype Characters in Selfing and Open Pollinated Sweet Corn (Zea mays Var. Saccharata Sturt). Science Innovation, 14(2), 145-155.

Roessler, K., Muyle, A., Diez, C.M., Bousios, A., Stitzer, M.C., Seymour, D.K., Doebley, J.K., Liu, Q. and Gaut, B.S. (2019). The Genome-Wide Dynamics of Purging during Selfing in Maize. Nature Plants, 5, 980-990. https://doi.org/10.1038/s41477-019-0508-7

Saenong, S. (2018). Maize Seed Technology presented at the Seminar on Cerealia. Indonesia.

Siswati, A., Basuki, N. and Sugiharto, A.N. (2017). Characterization on Some Inbred Lines of Yellow Corn (Zea mays L.). Crop Agro, 3(1), 19 - 26.

Sutoro and Zuraida, N. (2015). Management of Maize Germplasm. Indonesian Center for Agricultural Biotechnology and Genetic Resources. Indonesia: IAARD press.

Trihatmojo, H., Soegianto, A. and Sugiharto, A.N. (2017). Pollen Effect on Several Cross-Pollination of Maize (Zea mays L.) on Cob Appearance and Cob Character. Crop Agro, 5(2), 208-216. 